DOI: $10.31862 / 2500-297 X-2019-4-22-38$

\title{
Е.А. Цветков
}

Казанский национальный исследовательский

технологический университет,

420015 г. Казань, Республика Татарстан, Российская Федерация;

Казанская православная духовная семинария, 420036 г. Казань, Республика Татарстан, Российская Федерация

\section{П.Д. Юркевич - основоположник отечественной систематической научной педагогики}

В статье рассматриваются основные положения педагогики проф. П.Д. Юркевича - незаслуженно забытого русского философа, педагога. Отмечается, что Юркевич первый в России решительно выступил против редукционизма, сведения психологии к физиологии, призывал исходить в педагогике не из утилитарных соображений, а из высших начал, «из духа». Приводятся и обсуждаются мысли Юркевича о цели воспитания, о теснейшей связи воспитания и обучения, противопоставление языческой и православной педагогики. Анализируются различные методики и формы преподавания Юркевича. Делается вывод, что все современные инновации в педагогике (кроме компьютерных технологий) уже были применены Юркевичем.

Ключевые слова: профессор Юркевич, православная педагогика, антропологическая полнота, методика преподавания, педагогические инновации

ССЫЛКА НА СТАТЬЮ: Цветков Е.А. П.Д. Юркевич - основоположник отечественной систематической научной педагогики // Педагогика и психология образования. 2019. № 4. C. 22-38. DOI: 10.31862/2500-297X-2019-4-22-38 


\section{E.A. Tsvetkov}

Kazan National Research Technological University, Kazan, Republic of Tatarstan, 420015, Russian Federation;

Kazan Orthodox Theological Seminary, Kazan, Republic of Tatarstan, 420036, Russian Federation

\section{P.D. Yurkevich - the founder of the national systematic scientific pedagogy}

The article examines the main concepts of pedagogy of Prof. P.D. Yurkevich undeservedly forgotten Russian philosopher and teacher. It is noted that Yurkevich was the first in Russia to strongly oppose reductionism, reducing psychology to physiology, and called for pedagogy to be based not on utilitarian considerations, but on higher principles, "from the spirit". Yurkevich's ideas about the purpose of education, the closest connection between education and training, and the contrast between pagan and Orthodox pedagogy are presented and discussed. Various methods and forms of Yurkevich's teaching are analyzed. It is concluded that all modern innovations in pedagogy (except computers) have already been applied by Yurkevich.

Key words: Prof. Yurkevich, Orthodox pedagogy, anthropological completeness, teaching methods, pedagogical innovations

CITATION: Tsvetkov E.A. Yurkevich - the founder of the national systematic scientific pedagogy. Pedagogy and Psychology of Education. 2019. No. 4. Pp. 22-38. (In Russ.) DOI: 10.31862/2500-297X-2019-4-22-38 


\section{Место П.Д. Юркевича в истории отечественной педагогики}

\section{О педагогике}

Прошли времена, когда функции педагога ограничивались сопровождением ученика в гимнасий или в палестру. За долгие века педагогика превратилась не просто в науку со своими многочисленными понятиями и развитым категориальным аппаратом, но и в один из ведущих институтов любого общества. Более того, по словам П.Д. Юркевича, о трудах которого $[10 ; 11]$ и пойдет речь в этой работе, уровень государства определяется, наряду с армией и экономикой, уровнем образования.

Принято считать, что, говоря об образовании, особенно религиозном образовании, необходимо подчеркивать нравственную сторону. Однако нельзя так редуцировать и, говоря философским языком, необходимо осуществлять образовательный процесс в полноте этики, гносеологии и онтологии.

Из всей плеяды замечательных русских педагогов этому требованию удовлетворял только один незаслуженно забытый, вычеркнутый большевистской цензурой Памфил Данилович Юркевич (1827-1873 гг.).

\section{Личность П.Д. Юркевича}

Только в новой России для многих начало открываться это имя, хотя оно занимало достойное место в известных обзорах прот. В. Зеньковского и Н.О. Лосского [2; 8]. Правда, и в них очень скупо отмечены основные вехи жизни этого замечательного человека. Так, у первого не отмечен факт, что Юркевич был профессором Киевской Духовной академии и, как пишет В.О. Ключевский в своих воспоминаниях: ее «украшением» и «перетащили-таки его из Киева к досаде Киевской академии» $[11$, с. 530$]$, а у второго не отмечен киевский период.

Имеются только два квалифицированных разбора творчества Юркевича: у его ученика В.С. Соловьева и у Г.Г. Шпета. Кроме них можно отметить краткие очерки в «Философской энциклопедии»: Р.А. Гальцевой в статье «Юркевич» [7, т. 5] и А.И. Абрамова [5, т. 3, вступ. статья и примечания], хотя такого уровня мыслителей до него в России, по сути, и не было. Можно назвать, разве, Г. Сковороду, А.С. Хомякова, кн. В.Ф. Одоевского.

О педагогическом мастерстве Юркевича, чему и посвящена настоящая работа, можно судить и из воспоминаний Ключевского: «После каждой лекции в голове остается такое ясное представление о всем прочитанном, что стоит только употребить небольшое внимание, чтобы после быть в состоянии повторить весь ряд мыслей» [11, с. 531]. 


\section{Борьба Юркевича за полноту бытия}

Жизненные перипетии Юркевича во многом связаны с его мужественной гражданской, философской и православной позицией. Нужно хорошо представлять особенности эпохи, когда совпало философское пробуждение русского сознания и «призрак коммунизма» добрался до России.

Можно проследить этапы этого альянса, начиная с Гегеля, который считал, что в движении своей мысли человек может подняться от уровня субъективного мышления, «субстанциального образа существования» до уровня абсолютного умозрения или, говоря современным языком, как выходит сознание из безразличного покоя непосредственной жизни, из «естественного горизонта», «жизненного мира», по Гуссерлю, поднимается над житейской суетою, приходит к «озабоченности», по Хайдеггеру, ощущает «предельную захваченность», по Тиллиху; «начинается философская жизнь, как новый модус или новая ступень народного существования...» [8, с. 234].

Далее начинается разложение гегельянства у Фейербаха, который в своей критике и религии, и гегелевского идеализма апеллировал к психологическим особенностям антропологической структуры человека, совершенно неубедительно и бездоказательно (едва ли не на уровне Крития и Евгемера) декларируя, что человек сам бессознательно и непроизвольно создает по своему образу Бога, приписывая Ему все свои атрибуты, отображая на Него свою деятельность, а затем уже возникает культ. Душу, как мы видим, он еще не отрицал. Просто «приземлил» человека.

Дальше - больше. Начинается, в погоне за «обоснованием» единства человека, сведение психических явлений к физиологии. Вундт пытался понять человеческий разум, изучая составные части человеческого сознания так же, как при изучении сложного химического вещества его разбивают на составные элементы. Таким образом Вундт представлял психологию наукой, схожей с физикой и химией, в которой сознание есть набор разделяемых и опознаваемых частей (структурализм). Этот наивный подход был в дальнейшем отметён гештальтпсихологией (несводимость целого к его частям; аналог в ядерной физике - дефект массы).

Таким образом, полем битвы стала антропология, два взгляда на полноту человека. Один - христианский: «Сам же Бог мира да освятит вас во всей полноте, и ваш дух и душа и тело во всей целости да сохранится без порока в пришествие Господа нашего Иисуса Христа» (1 Фесс. 5:23), другой, дух отсекающий, - материалистический, манифестацией 
которого стала статья Чернышевского «Антропологический принцип в философии» (1860 г.). Ее трудно анализировать, т.к. «написана она небрежно, очень не выдержана в отношении систематического развития основной мысли... Под именем “антропологического принципа" излагается лишь очерк “новой” антропологии - без всякого отношения к философии» [2, с. 133].

Юркевич не мог пройти мимо бездарности и узости этого манифеста и написал достойную отповедь. Отметим лишь несколько характерных мест у Чернышевского и комментарии Юркевича на них.

1. В своем стремлении свести психологию к физиологии Чернышевский пишет: «Философия видит в нем (человеке. - E.Ц.) то, что видит медицина, физиология, химия; эти науки доказывают, что никакого дуализма в человеке не видно», на что Юркевич резонно отмечает: «Какая же тогда надобность в этой науке» [11, с. 112]. Видна справедливость оценки прот. В. Зеньковским уровня философии Чернышевского, не видящим различия философского и «наивного» реализма.

2. Чернышевский пишет: «Психология говорит, что самым изобильным источником обнаружения злых качеств служит недостаточность средств к удовлетворению потребностей, ...После потребности дышать (продолжает психология) самая настоятельная потребность человека есть и пить». Юркевич иронизирует: «Что скажет естествоиспытатель, если он послышит об этих великих открытиях строгого психологического анализа, именно, что голод заставляет человека воровать, особенно же, что человек имеет потребность дышать, есть и пить» [10, с. 113]. Ирония справедлива, т.к. именно в это десятилетие процветал «Клуб червонных валетов» - шайка молодых мошенников, вымогателей, фальшивомонетчиков и т.п., судившаяся в феврале 1877 г. (около 50 человек, преимущественно выходцев из богатых семей) [6, с. 591].

«Чернышевский хочет говорить о человеке как о существе, имеющем желудок и голову, кости, жилы, мускулы и нервы» [2, с. 134], пишет прот. В. Зеньковский, «что ощущение есть предмет так же данный для внешнего физиологического опыта, как сжатие и растяжение мускулов, движение крови, химическая переработка пищи в желудке и т.д.» [Там же, с. 111-112], хотя «ясно, что мысль не имеет пространственного протяжения, ни пространственного движения, не имеет фигуры, цвета, звука, запаха, вкуса, не имеет ни тяжести, ни температуры; итак, физиолог не может наблюдать ее ни одним из своих телесных чувств» $[11$, c. 115$]$.

И здесь Юркевич, как настоящий ученый, находит глубокое различие между естествознанием и материализмом, справедливо отмечая, «что естествознание изъясняет человеческий организм из материальных 
оснований, а материализм из этих оснований изъясняет все существо человека, всего человека» [11, с. 119]. В дальнейшем А.Ф. Лосев разовьет эту мысль: «Материя - одно из таких законнейших и необходимейших понятий человеческого разума. Почему я должен вырывать одно понятие из цельной диалектической системы всех понятий вообще, ставить его в центр всего и по его имени называть всю свою философскую систему? Все абстрактные понятия в одинаковой мере абсолютны, и нет никаких логических оснований одно из них абсолютизировать в ущерб другому» [3, с. 507]. И далее Лосев призывает материалистов признать, что этот их «миф получает абсолютную утвержденность в мысли, т.е. становится догматом» [Там же].

3. Упорствуя в своих редукционистских устремлениях, Чернышевский заявляет: «Соединение разнородных качеств в одном предмете есть общий закон вещей», на что Юркевич замечает: «В самом деле, не миф ли это, когда нам говорят, что в вещах количественное различие переходит в качественное? Это превращение количества в качество, величины в свойство также непостижимо, как превращения, о которых говорит Овидий» [10, с. 125]. А в «Диалектике мифа» Лосева читаем: «Ведь это же подлинное чудо - появление вещей из материи. Возьмите несколько деревянных досок: ни на одной из них нет ровно никакого признака стола. Как же вдруг появляется стол или шкаф? Говорят, - из соединения досок и палок. Но ведь “шкафности" не было ни в одной доске и ни в одной палке. Как же она появилась из соединения досок или палок? У вас в кармане нет ни гроша, и у меня в кармане нет ни гроша: как же появится вдруг грош, если мы соединим наши с вами карманы? Ясно, что должно совершиться чудо. Материалисты верят в чудесное, сверхъестественное воплощение чуть-чуть только не Отца, а пока только какой-то глухой и слепой матери-материи...» [3, с. 511].

4. Утверждение Чернышевского, объясняющего «происхождение мира единственно из обстоятельств», вызывает восклицание Юркевича: «Это опять мифология, которая допускает многих действительно творящих богов, называя их обстоятельствами» [10, с. 126].

5. Подверг Юркевич критике попытку Чернышевского уравнять нравственность животного и человека.

6. И, наконец, итог «философских размышлений» Чернышевского. Изучая опыт социальных движений в Западной Европе, Чернышевский пришел к выводу, что не буржуазный либерализм поможет избежать капитализма, а крестьянская народная революция путем ликвидации помещичьей собственности на землю, уничтожения существующей государственности. Сама же революция должна быть подготовлена 
организацией революционеров. Главные герои у него - нигилисты. Можно провести аналогию с сектой анабаптистов (1520 г.), которые принцип свободы в религиозной сфере, декларированный Лютером в 1517 г., провели в жизнь и в общественную, и в политическую, не останавливаясь при этом ни перед какими мерами произвола и насилия. Лютер назвал их исчадьями ада и проклял их в Виттенбурге. Но, и как позже в XIX в. в России, их проповеди овладели умами широких слоев населения и вызвали страшное брожение. Христианские храмы были разрушены, духовенство и состоятельные граждане - перебиты, имущество зажиточных граждан было отдано в общее пользование (что произошло и в России в 1917 г.), была допущена и общность жен (было и такое в Саратовской губернии). Разгул либерализма, человекобожия и нигилизма хорошо описаны в известных романах Достоевского и Лескова. О травле, которой подвергались носители традиционных ценностей, позднее перешедшей в настоящий террор, тоже узнаем из этих романов.

«И эта утилитарно-моралистическая травма оказалась в русской душе особенно злокачественной и ползучей. В этом отношении очень показательна известная полемика “Современника” против Юркевича. Впрочем, это не была полемика, но травля. < ..> Но не столько старались опровергнуть противника, сколько его опозорить и навлечь на него неприятные подозрения» [8, с. 290]. «Критика материализма у Юркевича... вызвала резкие и грубые статьи и заметки в русских журналах; имя Юркевича в русских радикальных кругах долгое время поэтому было связано - без всяких оснований - с представлением о “мракобесии" и мешало усвоению замечательных построений Юркевича» [2, с. 117-118].

«Самоуверенность автора в том, что только в направлении ему близком, есть истина, - переходит постоянно у него в развязность, презрительное отношение ко всем инакомыслящим. ... Теперь же Чернышевский становится нетерпимым, раздражительным, докторальный тон его становится невыносимым» [Там же, с. 133].

Статья Юркевича была замечена в верхах, и его как оплот традиционных православных ценностей пригласили возглавить кафедру философии в МГУ (1861 г.). Научных работ было им написано немного, но все они оказали существенное влияние на русскую мысль. Так, например, его работа «Сердце и его значение в жизни человека», несомненно, повлияла на работу Б.П. Вышеславцева «Сердце в христианской и индийской мистике». Можно упомянуть про магистерскую и докторскую диссертации С.М. Соловьева. Во многом Юркевич, отчасти и через Соловьева, повлиял на А.Ф. Лосева, как видно из приведенных выше цитат. 


\section{Педагогическая деятельность П.Д. Юркевича}

Наряду с научной деятельностью, Юркевич много внимания уделял и преподаванию, как в МГУ (на его лекции ходили попечитель и ректор университета, многие профессора, причем некоторые отменяли свои лекции, чтобы послушать Юркевича), так и на ниве народного просвещения, в учительской семинарии военного ведомства, где им написаны «Чтения о воспитании» (1865 г.) и «Курс общей педагогики» (1869 г.). «Несколько статей и книг Юркевича были посвящены вопросам воспитания» [2, с. 117].

Травля со стороны либеральной общественности, а она, как и во все времена, занимала ведущие позиции в журналистике, в немалой степени коснулась и педагогической деятельности Юркевича. «Желчная печать не упускала ни одного случая, и нападки на ненавистного мыслителя продолжались непрерывно. Юркевича уподобляли даже экскрементам Диогена» [4, с. 102]. Приведем лишь один пример нападок со стороны П.Н. Ткачева, активного участника революционного подполья 1860-х гг., публициста, рассматривающего философию лишь как инструмент преобразования мира на основе «справедливого социального устройства», лишенного метафизической утонченности истинного философа, заменившего ее агрессивностью и дерзостью. Он сравнивает мысли Юркевича с «плодами: снаружи они заманчивы и, по-видимому, много обещают; внутри они наполнены какою-то гнилою жидкостью, издающей отвратительный, одуряющий запах»; «философия [Юркевича] сводится к магии и кабалистике», «фантастические бредни ребяческих умов» [6, с. 11], «полицейские советы» [Там же, с. 27], «вот вам изнанка мистического идеализма московских чернокнижников» [Там же, с. 35]. По Ткачеву, мысли Юркевича - это «гнусная попытка под личиной идеалистической фразеологии и туманной мистики оправдать все дикое и безобразное, все нелепое и злое, все отвратительное бессмысленное, что только имеет какое-нибудь место, ...» [Там же].

Более высокая научная репутация в глазах «либеральной общественности» и в дальнейшем более счастливая судьба наследия ожидала К. Ушинского. Приняв «правила игры», он сразу сузил антропологическую сущность человека. Первая же глава в его труде «Человек как предмет воспитания, опыт педагогической антропологии» называется «Нервная система» (что дало повод Юркевичу иронично заявить о «ненормальном состоянии нервов самих педагогов», которые сводят душу к «рефлексам своего тела» [10, с. IV]). О духе же Ушинский собирался поговорить лишь в третьем томе, который, что символично, так и не был написан. И дело не в кончине Ушинского в 1871 г., а в том, что 
ему просто нечего было бы сказать, т.к. и философский уровень Ушинского невысок.

Деятельность еще одного значительного педагога, А.С. Макаренко, могла происходить только в условиях жесточайшего идеологического прессинга, под патронажем и в сотрудничестве с соответствующими органами. Какое уж тут воспитание; строилось платоновское «Государство», в худшей его интерпретации.

По-настоящему научный подход в педагогике демонстрировал лишь Юркевич. Любое умозаключение - дедуктивно, и исходить в своих дискурсах следует из более общих понятий, что и делает Юркевич, говоря, что «воспитание - судьба духа» [10, с. IV], исходя из антропологической полноты человека. Если представить, что возникла бы необходимость, по примеру Плутарха, составить «Сравнительные жизнеописания»: Юркевич и Ушинский, Платон и Аристотель, Достоевский и Толстой, то автор, в соответствии с духом данной статьи, в отличии от него, несомненно склонился бы не ко вторым, а к первым именам, конечно же не отрицая значимость и вторых.

В данной работе сделана попытка, едва ли не первая в России, осветить, хотя бы в тезисном виде, основные моменты в педагогическом наследии Юркевича. Структура данной работы следует примерно структуре «Курса» Юркевича [10].

\section{Цели образования по П.Д. Юркевичу}

\section{Отличие христианской педагогики от языческой}

Во все времена, у всех народов существовала система встраивания человека в материальную и духовную жизнь социума. Научно обоснованная методика этого процесса и есть педагогика. Юркевич, анализируя педагогику в языческие времена, дает общую ее формулу: «естественный эгоизм» родителей (утешение и помощь в старости, поминание детьми, чтобы легче жилось в потустороннем мире и пр.) и государства (это будущие защитники и «налогоплательщики» [Там же, с. 4]). Для христианства же воспитание детей - служение всему человечеству, стремление воспитать в детях «чистый образ Богоподобного человека» [Там же].

\section{Основная чель православной педагогики}

Цель воспитания, по Юркевичу, совпадает с целью жизни. «Многосложные же отношения, которые заключаются в понятии о цели жизни» [10, с. 9] сводятся, в конечном итоге, к Спасению, к достижению жизни вечной, подготовкой к которой и является жизнь земная. «Воспитание - 
судьба духа» - говорит Юркевич [10, с. IV]. Так как мы не знаем будущности воспитанника, то воспитывать надо так, «чтобы он был уготован на всякое благое дело» [Там же, с. 30]. Каким образом «насаждать добро в сердце человека» [Там же, c. VI] - это вечный вопрос и нет универсального рецепта и формулы. Воздействовать надо и на разум, и на волю, и на чувствования, во всей антропологической полноте [Там же, с. 7].

Как истинный ученый, Юркевич пытается придать педагогике понятийный характер, разделяет ее на теорию воспитания и теорию обучения [Там же, с. 44] (что прописано и в Законе об образовании РФ, поставивший воспитание на первое место). «Дитя воспитывается с первых мгновений жизни» [Там же], но оно еще не способно к обучению и получает его через воспитание. В зрелом же возрасте человек получает воспитание через обучение. Здесь такое же диалектическое единство, как вера и знание.

\section{Возможные альтернативные чели}

Анализируя «все споры о цели нашего существования» [10, с. 11] с древнейших времен, Юркевич сводит их к двум мнениям: «одни видят эту цель в счастии, другие - в добродетели» [Там же]. Вопрос - с чем соединяет человек понятие счастья. Но в любом случае, «самое искание счастия есть уже несчастие» [10, с. 15]. Лучшее же определение добродетели Юркевич находит у Аристотеля: «добродетель есть то, что признает добродетелью человек добродетельный» [Там же, с. 11].

Идея добра таким рефреном проходит через творчество Юркевича, что, несомненно, повлияло на выбор его учеником - C.М. Соловьевым - названия его фундаментального труда: «Оправдание добра». Прочитав же у Юркевича фразу: «Счастливым каждый может и хочет быть по-своему, и все правила счастья индивидуальны, но нельзя быть по-своему честным или добросовестным...» [Там же, с. 13], каждый образованный человек вспомнит первую фразу в «Анне Карениной» (Толстой внимательно следил за педагогической литературой).

Ни в коем случае не принимает Юркевич утилитаризм в педагогике. В дилемме «Нужда от низшего, или любовь к высшему», он безоговорочно считает, что «во все воспитательные меры нужно вносить высший моральный дух» [Там же, с. 10].

Не обошел Юркевич и только-только возникшую проблему патриотизма и космополитизма. Так же, как человек разводит в саду яблоки, груши и вишни, а не какой-то «овощь вообще» (орфография Юркевича), так и «все, что имеет действительность, есть всегда и необходимо частное и что космополитический характер получает оно вследствие своего внутреннего достоинства...» [Там же, с. 25-26]. 


\section{Юркевич об университетах.}

«Развитие» университетов от уровня «1.0» до «4.0»

В соответствии с принятой в настоящее время классификацией, уже Ученые советы вузов принимают решение о переводе обучения на уровень «3.0».

Платон об образовании: «Образование, имеющее своим предметом и целью деньги, власть или какую иную мудрость, лишенную разума и справедливости, низко и неблагородно, да и вовсе недостойно называться образованием» [5, т. 4, с. 92].

Упоминая средневековые университеты («1.0»), Юркевич пишет о «благородном духе той эпохи, которая разделяла с Платоном убеждение, что знание есть добродетель» [11, с. 523]. Богословский, медицинский и юридический факультеты символизировали единство души и тела, как тела человеческого, так и социального.

В «гумбольтовских университетах» («2.0») он еще видит какой-то поиск истины, «независимость от мотивов эгоизма» [Там же, с. 525]. Но предсказал Юркевич и современный тренд - университеты «3.0» и даже уже - «4.0»: «превращение университетов в политехнические школы» [Там же, с. 526].

В свое время лауреат Нобелевской премии Е. Вигнер прямо писал: «Хотя об этом не принято говорить вслух, мы все знаем, что с общечеловеческой точки зрения цели нашей науки намного скромнее, чем цели, например, древнегреческой науки, и что наша наука с большим успехом увеличивает нашу мощь, чем наделяет нас знаниями, представляющими чисто человеческий интерес» [1, с. 176]. А ведь Вигнер, на наш взгляд, еще идеализировал действительность. О целях явных или неявных хозяев жизни писал еще Платон: «Они надеются в один прекрасный день изобрести Атланта, еще более мощного и бессмертного, способного еще тверже удерживать все на себе, и нисколько не предполагают, что в действительности все связуется и удерживается благим и должным» [5, т. 2, с. 58]. О попытке камуфляжа истинных целей правителей писал и Шеллинг: «Ибо, к примеру, осуществление совершенного правового строя, совершенное развитие понятия свободы и все тому подобное все это в своем скудном содержании одновременно слишком безосновно, чтобы дух мог найти в этом точку покоя» [9, т. 2, с. 355]. Об этом не менее ярко писал и Юркевич, говоря о тенденции «помещать каждую науку в область средств и разобщать ее системой целей, которые при этом навязываются нам только грубым механизмом личных нужд и склонностей...» [11, с. 525]. Получается, годы в вузе нужны лишь для приобретения специальной учености как «полезный инструмент для добывания различных выгод в человеческом обществе» [Там же], ничем не напоминая ему о его высшей личности. 


\section{О воспитании}

\section{Воспитатель}

В процессе образования встречаются трое - воспитанник, воспитатель и изучаемая дисциплина, на которой, как на оселке, шлифуется и сам ребенок. Воспитатель должен обладать искусством изменения душевной жизни воспитанника, но «искусством, управляемым наукой» [10, с. 39-41] (как принято говорить, разум должен управлять волей или, как предписывает Писание: «Да будет воля Твоя»); с одной стороны, «сокрушать своеволие», с другой - находить ту грань, за которую он не должен заходить, чтобы не помешать свободному развитию ребенка.

Необходимо воспитателю быть тонким психологом, уметь переместиться в сердце воспитанника, «испытать все особенности его чувств и стремлений», иметь «художественный глаз, который видит действительность с ее индивидуальными свойствами, а не останавливается на отвлеченном очерке вещи» [Там же, с. 67]. И Юркевич много рассуждает о троякой любви, которой определяется «искусство и совесть воспитателя»: «любовь к истине, к ученикам, к добру» [Там же, с. 244-248]. О воспитателе: [Там же, с. 64, 129].

\section{Воспитанник}

Воспитанники - это дети, и Юркевич пишет: «Так как дети имеют право быть детьми, то воспитание не должно питать детей пищею, которая несродна их возрасту» [Там же, с. 51]. Необходимо учитывать индивидуальные особенности ребенка, ведь «по-разному дух погружен в тело» [Там же, с. 72]. Очень пространно Юркевич рассуждает о телесной конституции и о темпераменте.

Пути, которые намечает Юркевич, чтобы «очеловечить человека» [Там же, с. 33] направлены на то, чтобы человек потом сам, как сказал почти через сто лет Нобелевский лауреат по литературе Г. Гессе, «всю жизнь вочеловечивался».

\section{О гуманистической педагогике}

Уже во времена Юркевича понятие гуманности так укоренилось в сознании педагогов «и пустило столь разнообразные разветвления», что ему пришлось углубиться в рассмотрение этого понятия, сделать вывод, что наука не нашла и не найдет общей формулы человечности, что «гуманность равняется христианству» [Там же, с. 20], что «само воспитание - высшая и существеннейшая форма гуманности» [10, с. 24]. Юркевич дает сжатую формулу христианской гуманности: «в признании неискоренимых основ добра в сердце каждого 
человека» [10, с. 21]. «Где дух, там и свобода» [Там же, с. 34]. В другом месте Юркевич пишет, что понятие «человечность» так расплывчато, что «каждый помещает в нем содержание, какое находит сообразнейшим с системой своих убеждений» [Там же, с. 19]. Нельзя превращать обучение в игру. Невозможно воспитывать детей путем «возбуждения в них приятных ощущений, пытаясь заменить добросовестный труд игрою и высшие принципы - непосредственными естественными влечениями» [Там же, с. 18].

Вот этим и грешат современные «гуманистические» инновации. Если вспомнить, что в основе этой педагогики лежат откровения ее столпа Я.А. Коменского, то понятно, что такая педагогика, видящая в ребенке «микрокосмос, который в состоянии объять макрокосмос», является просто вариантом человекобожия. Такая педагогика ведет по пути развития не личности, а индивидуальности. Говоря современным философским языком, Юркевич четко разделял теономное, гетерономное и автономное мышление.

\section{О наказаниях}

Часто возвращаясь к понятию «человечность», Юркевич пишет об издержках гуманитарной педагогики: «Так, когда это понятие исключает при воспитании серьезность, строгость, дисциплину, послушание, твердый порядок, оно делается источником опасных заблуждений» [Там же, с. 19]. Как практический педагог, Юркевич почти сто страниц посвящает конкретным воспитательным мерам. Там он много рассуждает о диалектике свободы и принуждения, поощрения и наказания; выстраивает цепочку: «надзор», «наставление», «напоминание», «похвала и порицание», «обещание и угроза» [Там же, с. 102-137].

Особенно «либеральная общественность» не простила Юркевичу его глубочайшие рассуждения о наказаниях, хотя Юркевич понимает этот термин в его исконном смысле, как наказ, увещевание. Юркевич настаивает на необходимости дать воспитателю так называемое «отеческое право, т.е. право отвечать за принятую карательную меру только пред своей совестью и пред Богом» [Там же, с. 184]. В противном случае «воспитатель превращается в чиновника, который... не произведет на них лишнего доброго влияния, не сообщит им лишней разумной мысли, не пожертвует для их блага лишним усилием и т.д.» [Там же].

Отмечает Юркевич детскую жестокость: «часто с полным сознанием, с полною намеренностью воспитанники хотят раздражить самого воспитателя, и это желание будет пробуждаться тем легче, чем более бесправен и беззащитен воспитатель» [10, с. 184-185]. Примерно эту же мысль о детской жестокости можно найти потом в «Братьях Карамазовых». 
Современный либерализм отобрал право педагога даже на простое одергивание ребенка.

Невозможно привести все бесчисленные древние тексты многих народов о необходимости наказаний. Вспоминается самый краткий, греческий, который приводит Гете в качестве эпиграфа к своей «Поэзии и правде»: «О $\mu \eta \delta \alpha \rho \varepsilon เ \varsigma \alpha v \theta \rho \omega \pi о \varsigma$ оv $\pi \alpha \imath \theta \varepsilon v \varepsilon \tau \alpha \imath »$ (не наказуемый человек - не обучаемый).

\section{Обучение}

\section{Божественная педагогика}

Еще Платон писал о том, что «отсвет красоты небесной» всегда можно найти и в чувственном мире [5]. Можно перенести эти слова и на социальные институты, в том числе и на педагогику (Платон был бы не против). Можно говорить о педагогике земной и небесной. В Писании много говорится о божественной педагогике Христа. «Мягкая» пища и «твердая» пища. Образы, притчи, анализ и, наконец, понимание учениками смысла Спасения и пути достижения жизни вечной. Налицо корреляция божественной троичности и троичности в педагогике. Предельный образ - Бог-Отец, предельный логос Бог-Сын и, наконец, предельный синтез благодаря творческому началу, Богу Святому Духу.

\section{Возрастная педагогика}

Тончайше проработаны у Юркевича особенности воспитания и обучения ребенка в зависимости от возраста, далеко уйдя от классических схем Аристотеля, Руссо и др. Как тщательно прорисовывает он подвижность души дитяти, как и «его легкого тела», проникновенно говорит об одинаковом участии, с каким ребенок «глядит на разнообразнейшие сцены действительности», участвует в них всеми модусами души и как с возрастом «нужды делают нас односторонними» [10, с. 47].

Далее эти многочисленные образы помогают переходить к понятийному мышлению и, наконец, старшеклассник уже способен разлагать явления на составные части и создавать новые образы. Сначала слова, потом различает звуки и слоги, потом строит новые слоги и слова: образ - анализ - синтез. Нарушение этой триады приводит порой к ужасающим «инновациям» в педагогике. Так в 1970-е гг. наши школы едва не захлестнула, с «нелегкой руки» академика Колмогорова, мода, минуя арифметику, изучать сразу алгебру. Только выпускники школ, освоившие эти ступени, уверенно владеющие изложенной триадой, достойны продолжать обучение в вузах. 


\section{Методика преподавания}

Воспитание и обучение представляют из себя целостную структуру, включающую в себя кроме глобальных целей и общих рекомендаций еще и конкретные действия преподавателя, т.е. методику. Любое обучение, по Юркевичу, будет эффективно только при его наглядности. Много внимания он уделяет примерам, упражнениям, экзаменам, как форме отчетности, всем тонкостям практического усвоении дисциплин $[10$, c. $255,268,300,303]$.

Много пишет он о различных методах обучения - «созерцание, анализ и синтез» [Там же, с. 255], которые он затем развивает в Приложениях [Там же, с. 259-260]. В §80 приводятся применяемые «формы обучения». В современной терминологии: пассивная, когда учитель просто сообщает какие-то сведения, и активная, которую он делит на три вида: катехизическая - учитель сам задает вопросы и сам дает на них ответы, сократическая - учитель ставит вопросы и ученик дает ответы, и, наконец, диалогическая - «когда не только учитель предлагает вопросы ученикам, но и ученики учителю» [Там же, с. 257-258].

Связь воспитания и обучения Юркевич демонстрирует и на примеpax попечительства о теле. Упомянув в начале обширного Приложения об известном афоризме Ювенала о здоровом теле и здоровом духе, затем почти сто страниц посвящено этому попечительству. Достаточно двух примеров о попечительстве зрения: «Нужно противодействовать лени, вследствие которой дети при письме и чтении наклоняют голову к столу более чем следует...» [Там же, с. 345], «Дети должны сидеть во время занятий так, чтобы свет не падал ни спереди, ни справа...» [Там же, с. 347]. «Сидеть они должны на определенном месте, не склоняя головы на скамью и не подпирая ее руками; ...установить ноги на пол, не поджимая их под скамью и не складывая их одна на другую соблюдение всех этих мелочных условий чрезвычайно благоприятно для поддержания доброго состояния души и тела» [Там же, с. 97-98].

И это Юркевич писал во времена, когда, по Тютчеву, уже «не плоть, а дух растлился». Для современного же либерала эти наставления вообще кажутся дикостью. Развязность стала нормой. Сейчас это, правда, называют «человеческим фактором», а ведь все катастрофы из-за пренебрежения мелочами.

\section{Наследие П.Д. Юркевича}

Многим покажется, что все изложенное слишком тривиально и является общим местом в педагогике. Но следует учесть, что все это Юркевич впервые изложил на русском языке, а многое вообще впервые. 
Данная работа - лишь слабый отсвет глубокого и обширного педагогического наследия Юркевича, которое требует своей разработки. Больше того, среди современных инноваций мы не найдем ничего, о чем бы не сказал этот великий педагог.

Основываясь на Писании, привлекая опыт и отечественной педагогики, и зарубежный опыт, Юркевич фактически показал, что истинная педагогика может исходить только из высших начал, из «духа», что имплицитно и неосознанно присутствует во всех лучших педагогических системах у многих народов.

Замалчивание этого имени в море педагогической литературы, даже у таких авторов как прот. В. Зеньковский, лишь повторивший все сказанное Юркевичем, - это необъяснимый феномен.

\section{Библиографический список / References}

1. Вигнер Е. Этюды о симметрии. М., 1971. [Vigner E. Etyudy o simmetrii. [Studies on symmetry]. Moscow, 1971.]

2. Зеньковский В.В., прот. История русской философии. Т. 1. Ч. 2. Л., 1991. [Zenkovskiy V.V. Istoriya russkoy filosofii [History of Russian philosophy]. Vol. 1. Part 2. Leningrad, 1991.]

3. Лосев А.Ф. Диалектика мифа. Из ранних произведений. М., 1990. [Losev A.F. Dialektika mifa. Iz rannikh proizvedeniy [The dialectic of myth. From early works]. Moscow, 1990.]

4. Лосский Н.О. История русской философии. М., 1991. [Losskiy N.O. Istoriya russkoy filosofii [History of Russian Philosophy]. Moscow, 1991.]

5. Платон. Собр. соч. в 4-х тт. М., 1990-1994. [Plato. Sobranie sochineniy [Works]. Moscow, 1990-1994.]

6. Ткачев П.Н. Кладези мудрости российских философов. М., 1990. [Tkachev P.N. Kladezi mudrosti rossiyskikh filosofov [Fountains of wisdom of Russian philosophers]. Moscow, 1990.]

7. Философская энциклопедия: В 5 т. / Под ред. Ф.В. Константинова. М., 1970. [Filosofskaya entsiklopediya [Encyclopedia of Philosophy]. F.V. Konstantinov (ed.). Moscow, 1970.]

8. Флоровский Г., прот. Пути русского богословия. Киев, 1991. [Florovskiy G. Puti russkogo bogosloviya [Ways of Russian Theology]. Kiev, 1991.]

9. Шеллинг Ф.В.Й. Соч. в 2-х тт. Т. 2. М., 1989. [Schelling F.W.J. Sochineniya [Works]. Vol. 2. Moscow, 1989.]

10. Юркевич П.Д. Курс общей педагогики с приложениями. М., 1869. [Yurkevich P.D. Kurs obshchey pedagogiki s prilozheniyami [General pedagogy course with applications]. Moscow, 1869.]

11. Юркевич П.Д. Философские произведения / Под ред. В.С. Степина. М., 1990. [Yurkevich P.D. Filosofskiye proizvedeniya [Philosophical works]. V.S. Stepin (ed.). Moscow, 1990.] 
Сведения об авторе / About the author

Евгений Алексеевич Цветков - кандидат физико-математических наук, доцент; доцент кафедры физики, Казанский национальный исследовательский технологический университет; доцент кафедры богословия и философии, Казанская православная духовная семинария

Evgeny A. Tsvetkov - PhD in Physics; associate professor at the Department of Physics, Kazan National Research Technological University; associate professor at the Department of Theology and Philosophy, Kazan Orthodox Spiritual Seminary

E-mail: tsvetkov_e@mail.ru 